\title{
Histopathological Diagnosis of Peptic Ulcer Biopsies in Koya City, Kurdistan Region, Iraq
}

\author{
Mehri Mirhaj Muhammadsalih* \\ Department of Medical Lab Technology, Koya Technical Institute, Erbil Polytechnic University, Erbil, Kurdistan Region, Iraq
}

\begin{abstract}
*Corresponding author:
Mehri Mirhaj

Muhammadsalih,

Department of Medical Lab

Technology, Koya Technical

Institute, Erbil Polytechnic

University, Erbil, Kurdistan

Region, Iraq.

E-mail: mehri.salih@epu.

edu.iq
\end{abstract}

Received: 20 October 2019

Accepted: 21 November 2019

Published: 20 December 2019

\section{DOI}

10.25156/pt.v9n2y2019.pp208-212

\section{A B S T R A C T}

Peptic ulcer disease is the common gastrointestinal disorder, which affects the high number of people during their life. The present study was carried out among 267 patients with different upper gastrointestinal symptoms, at the Department of Endoscopy, Shahid Dr.Khalid Hospital/in Koya city during $1 / 2018-1 / 2019$, all patients were assessed endoscopically and biopsies from both antral and body mucosa were taken for histopathological examination. The aim of this study was to determine the spectrum of histopathological biopsies of the gastric region with the distribution of peptic ulcer biopsies according to age and sex in Koya city, Kurdistan Region, Iraq. The study showed normal gastric mucosa histopathologically in $22(8.24 \%)$ cases and $245(91.76 \%)$ abnormal gastric mucosa histopathologically. Gastritis histopathologically was seen in $217(81.27 \%)$ of cases, chronic gastritis represented the highest relative frequency in this histopathologically diagnosed patients, where it was seen in $65.89 \%$ of the cases and acute gastritis was detected in $34.10 \%$ of the cases. Helicobacter pylori was detected in $82.77 \%$ of patients. A significant association was detected between chronic gastritis and $H$. pylori infection.

Keywords: Biopsy; Endoscopy; Gastritis; Helicobacter pylori; Histopathological examination; Peptic ulcer

\section{INTRODUCTION}

Peptic ulcer disease is common throughout the world and its relationship with Helicobacter pylori was long before established. A peptic ulcer is a sore or inflammation on the lining of the stomach or duodenum of the digestive system (Ganapathy and Suryadevara, 2016). Histopathological study of biopsy specimens is used to confirm the endoscopic diagnosis in suspected malignancy or to rule out in the endoscopically benign appearing lesions and also is performed for monitoring the course, determining the extent of disease as responses to therapy and for the early detection of complications (Sharma et al., 2015).

The human gastrointestinal tract which is long and tortuous is an important site for a wide variety of lesions, which includes congenital, inflammatory, and neoplastic conditions (Dacosta et al., 2002). Gastric disorders are one of the most commonly encountered problems in clinical practice. A variety of disorders can affect the stomach and gastrointestinal tract. The definitive diagnosis of gastric disorders rests on the histopathological confirmation, to facilitate the diagnosis of different lesions, endoscopic and histology are complementary (Pailoor et al., 2013) (Versalovic, 2003). There are several etiological types of gastritis, their different etiology being related to different clinical manifestations and pathological features (AlNuaimya and Faisal, 2019) (Poudel et al., 2013). Most of the patients have both gastric and duodenal ulcers at the same time and they have higher incidences to develop peptic ulcers more than once in their lifetime (U.S. Department of Health and Human Services, 2010). Sometimes, a peptic ulcer may develop above the stomach in the esophagus, but the occurrence of peptic ulcers in this region is less common in patients (Ramakrishnan and Salinas, 2007).

The primary cause of peptic ulcers is $H$. pylori a bacterium and is the second most common pathogen which affects the population of gastric related diseases (Calvino and Parra, 2010). H. pylori is a spiral shaped, basophilic, and Gram-negative bacillus that resides exclusively in the gastric mucosa (Yakoob and Hussainy, 2010). H. pylori has been established as a major etiological factor in the pathogenesis of chronic gastritis and gastric atrophy (Hassan et al., 2016). To arrive at the diagnosis of different lesions, endoscopic and histopathology are complementary (Versalovic, 2003). The aim of this study was to determine the spectrum of histopathological biopsies of the gastric region with the distribution of peptic ulcer biopsies according to age and sex in Koya city, Kurdistan Region, Iraq. 


\section{MATERIALS AND METHODS}

The present study was carried out among 267 patients with endoscopic biopsies and histopathological assessment, at the Department of Endoscopy, Shahid Dr.Khalid Hospital/in Koya city during 1/2018-1/2019. A total of 267 gastric biopsies were studied for 12 months from January 2018 to January 2019. Of these 267 cases, 158 were male and 109 were female.

Endoscopies were done in all the clinically diagnosed patients with peptic ulcer, biopsies from both antral and body mucosa were taken for histopathological examination. Specimens were processed and endoscopic biopsies placed into a labeled bottle containing $10 \%$ neutral formalin, were received in the Department of Surgery, Shahid Dr.Khalid Hospital. General examination for samples according to the general technique was done and then documented. Tissue processing of samples was done using an automatic tissue processor. Specimens were processed and embedded in the paraffin wax and were cut into sections of $5 \mu \mathrm{m}$ in thickness, all the slides were stained with hematoxylin and eosin, and Giemsa stain is used where it was needed.

The clinical and pathological data of the studied patients were reviewed and entered into a computerized database. The statistical analysis included (\%) and Chi-square test. $P \leq 0.05$ was considered statistically significant.

\section{RESULTS}

A total of 267 gastric biopsies were studied for 12 months from January 2018 to January 2019. Out of these 267 cases, 158 (59.17\%) were male and 109 (40.83\%) were female, the majority of cases were of male gender. The age range of patients was from 22 years to 86 years with a mean age of 54 years. The highest incidence was seen in $41-50$ years old patients or fourth decade, while the lowest incidence was seen in the seventh and second decades. The age and sex distribution of the study is shown in Table 1.

The endoscopic examination showed normal gastric mucosa in $90(33.70 \%)$ patients out of a total of 267 patients. The histopathological findings of these 90 patients showed $22(8.24 \%)$ normal gastric mucosa Figure 1, while $38(14.23 \%)$ males and $30(11.24 \%)$ females showed abnormal gastric mucosa, among them 19 (7.11\%) males and $12(4.49 \%)$ females showed antral gastritis, 13 (4.87\%) males and $10(5.99 \%)$ females showed body gastritis, and $6(2.25 \%)$ males and $8(3 \%)$ females showed both antral and body gastritis. The remaining 177 (66.30\%) patients revealed abnormal gastric mucosa (gastritis) endoscopically. On histopathological examination, 106 (39.70\%) males and
$71(26.59 \%)$ females showed abnormal gastric mucosa, among them $59(22.10 \%)$ males and $28(10.49 \%)$ females showed antral gastritis, $28(10.49 \%)$ males and 22 (8.24\%) females showed body gastritis, and $19(7.12 \%)$ males and $21(7.87 \%)$ females showed both antral and body gastritis.

Among the 217 (81.27\%) of a total of 267 patients with gastritis histopathologically, acute gastritis [Figure 2] was diagnosed in $74(34.10 \%)$ patients, while chronic gastritis [Figure 3] was detected in $143(65.89 \%)$ of the patients, sex distribution with their endoscopical and histopathological diagnosis is shown in Table 2.

\begin{tabular}{|c|c|c|c|}
\hline \multirow[t]{2}{*}{ Age group (years) } & \multicolumn{2}{|c|}{ Sex of the patients } & \multirow[t]{2}{*}{ Total (\%) } \\
\hline & Male & Female & \\
\hline $22-30$ & 8 & 10 & $18(6.74)$ \\
\hline $31-40$ & 44 & 32 & $76(28.46)$ \\
\hline $41-50$ & 58 & 38 & $96(35.95)$ \\
\hline $51-60$ & 18 & 8 & $26(9.74)$ \\
\hline $61-70$ & 22 & 12 & $34(12.73)$ \\
\hline$>71$ & 8 & 9 & $17(6.37)$ \\
\hline Total & 158 & 109 & $267(100)$ \\
\hline
\end{tabular}

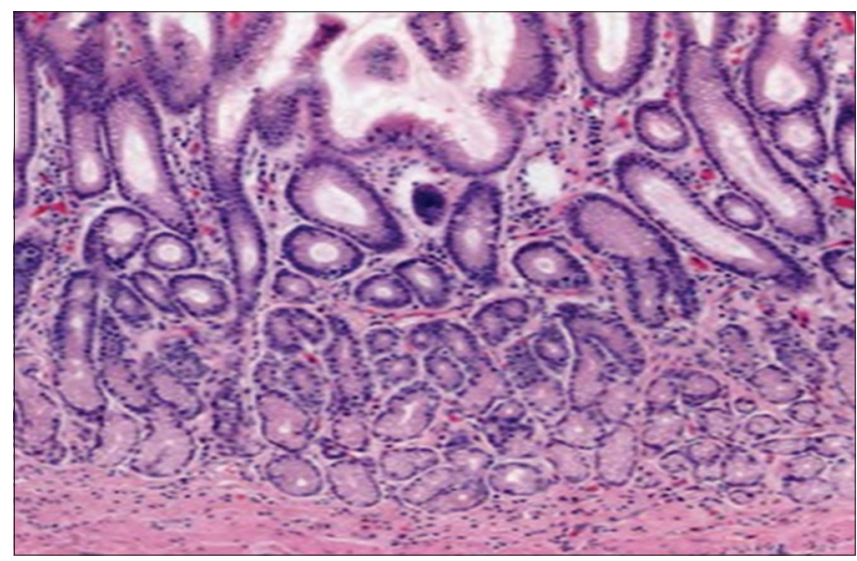

Figure 1: Photomicrograph showing the normal gastric mucosa (H\&E ×400)

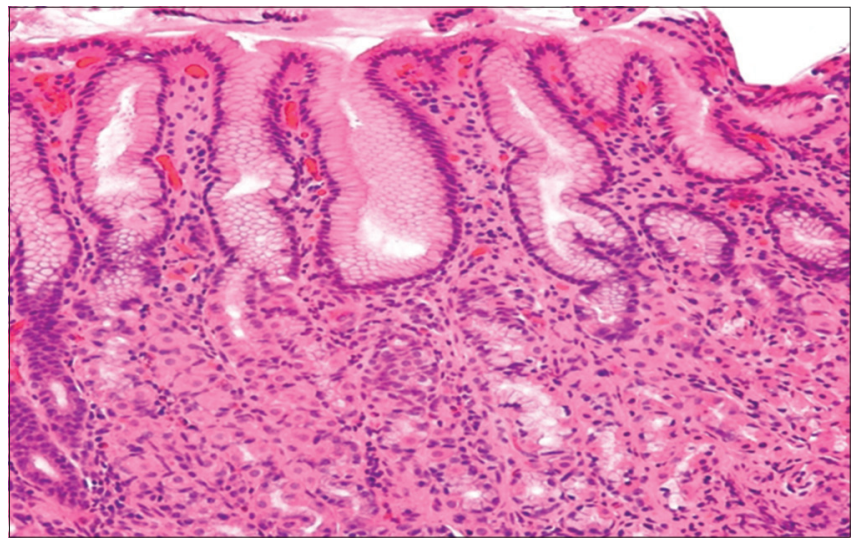

Figure 2: Photomicrograph showing superficial acute gastritis (antrum) (H\&E ×400) 
Table 2: Sex distribution with their endoscopic and histopathological diagnosis

\begin{tabular}{|c|c|c|c|c|}
\hline Features & Description & Male (\%) & Female (\%) & Total (\%) \\
\hline Endoscopical findings & Normal gastric mucosa & $52(14.97)$ & $38(14.23)$ & $90(33.70)$ \\
\hline \multirow[t]{4}{*}{ Histopathological findings } & Normal gastric mucosa & $14(5.24)$ & $8(3)$ & $22(8.24)$ \\
\hline & Antral gastritis & $19(7.11)$ & $12(4.49)$ & $31(11.61)$ \\
\hline & Body gastritis & $13(4.87)$ & $10(5.99)$ & $23(8.61)$ \\
\hline & Antral and body gastritis & $6(2.25)$ & $8(3)$ & $14(5.24)$ \\
\hline Endoscopical findings & Abnormal gastric mucosa & $106(39.70)$ & $71(26.59)$ & $177(66.30)$ \\
\hline \multirow[t]{3}{*}{ Histopathological findings } & Antral gastritis & $59(22.10)$ & $28(10.49)$ & $87(32.58)$ \\
\hline & Body gastritis & 28 (10.49) & $22(8.24)$ & $50(18.73)$ \\
\hline & Antral and body gastritis & $19(7.12)$ & $21(7.87)$ & $40(14.98)$ \\
\hline \multirow[t]{2}{*}{ Histopathological findings } & Acute gastritis & 34 (15.67) & $30(13.83)$ & $74(34.10)$ \\
\hline & Chronic gastritis & $96(44.24)$ & $47(17.60)$ & $143(65.89)$ \\
\hline
\end{tabular}

Table 3: The frequency of $H$. pylori according to the severity of gastritis

\begin{tabular}{lcc} 
Grade & \multicolumn{2}{c}{ H. pylori +ve } \\
\cline { 2 - 3 } & No. & $\%$ \\
\hline Normal gastric biopsy & 87 & $(39.36)$ \\
Acute gastritis & 47 & $(21.27)$ \\
Chronic gastritis & 87 & $(39.36)$ \\
Total & 221 & $(100)$ \\
\hline
\end{tabular}

H. pylori: Helicobacter pylori

By the use of a modified Giemsa stain, H. pylori was detected in $221(82.77 \%)$ of the patients. H. pylori was detected in $87(29.21 \%)$ patients with normal gastric biopsy, in $47(17.60 \%)$ patients with acute gastritis, and in $87(29.21 \%)$ patients with chronic gastritis, the frequency of $H$. pylori according to the acute and chronic gastritis is shown in Table 3.

No statistically significant relation found between normal findings with histopathological assessments of each antral $(P=0.07)$, body $(P=0.06)$, and both antral and body gastritis $(P=0.06)$, respectively, while a statistically significant relation found between abnormal gastric findings with histopathological assessments of each antral $(P=0.05)$, body $(P=0.05)$, and both antral and body gastritis, $(P=0.05)$, respectively, there was a very strong association between chronic gastritis and H. pylori $(P=0.00)$. The intercorrelation among various histopathological parameters with each other is shown in Table 4.

\section{DISCUSSION}

The study was conducted from January 2018 to January 2019, comprised 267 patients with endoscopic biopsies and histopathological assessment. Of these 267 patients, 158 (59.17\%) were males and 109 (40.83\%) were females, as shown in Table 1. In our study, the majority of cases were of the male gender, this is similar to the results of Sharma et al., 2015 and Jeshtadi et al., 2016. This could probably due to a large number of male genders attending

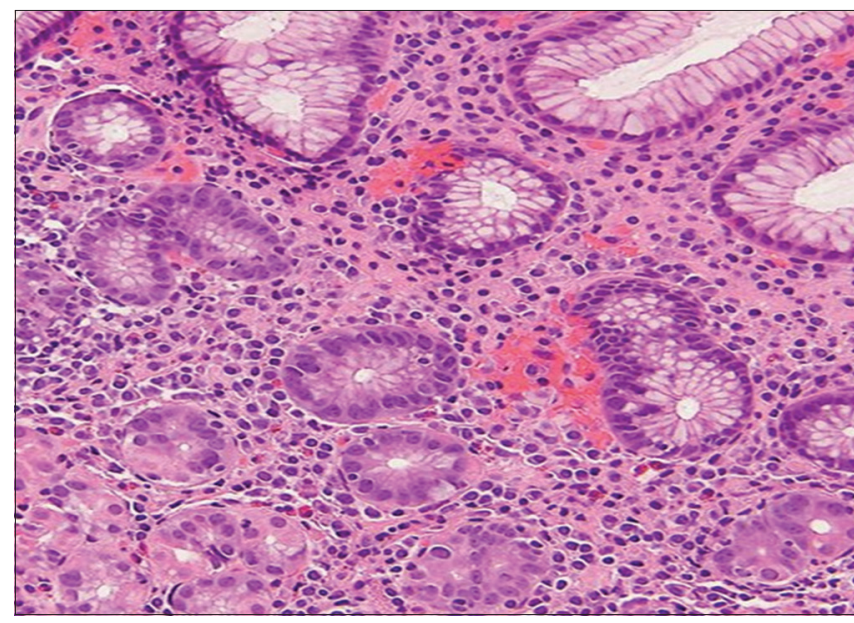

Figure 3: Photomicrograph showing chronic gastritis (body) (H\&E $\times 400)$

to the hospital compared to the female patients or females may be asymptomatic and may not come under medical attention. According to Sharma et al., 2015, this gender ratio favoring males could be reflecting of the fact that males are exposed to more risk factors than females, while Sultana et al., 2011 explained the reason for it by higher gastric acid level in male.

Gastritis, perhaps best defined as the inflammatory response of the gastric mucosa to injury, is an extremely common condition worldwide (Garg et al., 2012). The term gastritis has a broad histopathological and topographical spectrum that leads to different concepts of what gastritis is Al-Nuaimya and Faisal, 2019. The biopsy sampling of the gastric ulcer at diagnostic endoscopy provides useful information which helps in the diagnosis of various lesions (Sharma et al., 2015).

A study from Turkey showed that $94 \%$ of the patients who were diagnosed as having a normal upper gastrointestinal endoscopy were found to have gastritis after the histopathological diagnosis (Kasap et al., 2012), this is similar to the results of the present study, which 
Table 4: Intercorrelation among various histopathological parameters with each other

\begin{tabular}{lccccccc} 
Parameters & $\begin{array}{c}\text { Normal gastric } \\
\text { mucosa }\end{array}$ & $\begin{array}{c}\text { Antral } \\
\text { gastritis }\end{array}$ & $\begin{array}{c}\text { Body } \\
\text { gastritis }\end{array}$ & $\begin{array}{c}\text { Antral and body } \\
\text { gastritis }\end{array}$ & $\begin{array}{c}\text { Acute } \\
\text { gastritis }\end{array}$ & $\begin{array}{c}\text { Chronic } \\
\text { gastritis }\end{array}$ & $\begin{array}{c}\text { H. pylori } \\
\text { Normal gastric mucosa }\end{array}$ \\
Antral gastritis & - & 0.07 & 0.06 & 0.06 & 0.06 & 0.06 & 0.05 \\
Body gastritis & 0.04 & - & 0.00 & 0.00 & 0.05 & 0.05 & 0.05 \\
Antral and body gastritis & 0.03 & 0.00 & - & 0.00 & 0.03 & 0.5 & 0.04 \\
Acute gastritis & 0.05 & 0.00 & 0.00 & - & 0.05 & 0.05 & 0.04 \\
Chronic gastritis & 0.05 & 0.02 & 0.02 & 0.02 & - & 0.05 & 0.03 \\
H. pylori & 0.05 & 0.02 & 0.03 & 0.02 & 0.00 & - & 0.00 \\
\hline
\end{tabular}

The association between the histopathological parameters was assessed by means of Chi-square test. $P=0.05$ was considered statistically significant. ${ }^{*} P \leq 0.05$ is statistically significant. ${ }^{*} P=0.00$ is highly significant. ${ }^{*} P>0.05$ is not statistically significant. H. pylori: Helicobacter pylori

$90(33.70 \%)$ of the subjects were endoscopically normal, but only $22(8.24 \%)$ out of theses 90 cases were found to be histopathologically normal, the remaining $31(11.61 \%)$, $23(8.61 \%)$, and $14(5.24 \%)$ showed antral gastritis, body gastritis, and both antral and body gastritis, respectively, as shown in Table 2, these results are similar to that of Al-Nuaimya and Faisal, 2019 and Kaur and Raj, 2002 who showed that patients with a normal endoscopy were not necessarily histologically normal. There were 177 (66.30\%) patients with endoscopic abnormal gastric mucosa (gastritis). Their histopathological examination showed that $87(32.58 \%)$ had antral gastritis, $50(18.73 \%)$ showed body gastritis, and $40(14.98 \%)$ showed both antral and body gastritis. Among 217 (81.27\%) of the total 267 patients with gastritis histopathologically, acute gastritis was diagnosed in $74(34.10 \%)$ patients and chronic gastritis was detected in $143(65.89 \%)$ of the patients, these results are similar to Al-Nuaimya and Faisal, 2019, also with results of Ibis et al., 2009, who demonstrated that $85 \%$ of the subjects who were said to have gastritis endoscopically were found to have gastritis pathologically.

Peptic ulcer disease has shown a very high prevalence in Bangladesh and is important among the major chronic problems encountered by the physicians and surgeons (Nessa et al., 2001). In a developing country like Bangladesh, overcrowding, bad sanitation, and unhealthy practice favor the high prevalence of $H$. pylori in the population (Sultana et al., 2011).

The association of $H$. pylori with gastritis, duodenal ulcer, and gastric cancer has been reported by investigators from different countries all over the world (Akanda, 2006). According to Watari et al., 2014, there is a clear association between $H$. pylori infection and the development of peptic ulcer disease. In the present study, H. pylori was detected in $221(82.77 \%)$ of the patients, $87(29.21 \%)$ with normal gastric biopsy, $47(17.60 \%)$ patients with acute gastritis, and $87(29.21 \%)$ chronic gastritis, showing that the majority of the patients were developed chronic gastritis, these results were in agreement with that of Al-Nuaimya and Faisal, 2019, and Yakoob and Hussainy, 2010, which in their study revealed a significant association between $H$. pylori infection and activity of chronic gastritis, also in agreement with Watari et al., 2014, who pointed that the majority of patients infected with $H$. pylori develop acute gastritis which may spontaneously resolve. The ability of H. pylori to cause acute gastritis is best demonstrated from studies where healthy volunteers have been intentionally infected with the organism.

\section{CONCLUSION}

We concluded that the majority of cases were of the male gender, the highest incidence was seen in the fourth decade, while the lowest incidence was seen in the seventh and second decades. Chronic gastritis represented the highest relative frequency in the histopathologically diagnosed gastritis, where it was seen in $65.89 \%$ of the cases and acute gastritis was detected in $34.10 \%$ of the cases. $H$. pylori was detected in $82.77 \%$ of cases. A significant association was detected between chronic gastritis and $H$. pylori infection. Endoscopic and histopathological examinations of suspected gastric biopsies should go parallel and should be a substitute of each other.

\section{REFERENCES}

Akanda, M. R. 2006. Comparative study of Different Staining Methods for Detection of Helicobacter pylori in Gastric Biopsies with Associated Histological Changes. Department of Pathology Doctoral Dissertation, Thesis Bangabandhu Sheikh Mujib Medical University, Dhaka.

Al-Nuaimya, W. M. and H. M. Faisalb. 2019. Endoscopical and histopathological interpretation of gastritis in Nineveh Province. Ann. Coll. Med. Mosul. 41(1): 28-35.

Calvino, F. M. and C. T. Parra. 2010. Helicobacter pylori and mitochondrial changes in epithelial cells. The role of oxidative stress. Rev. Esp. Enferm. Dig. 102(1): 41-50.

Dacosta, R. S., B.C. Wilson and N. E. Marcon. 2002. New optical technologies for earlier endoscopic diagnosis of premalignant gastrointestinal lesions. J. Gastroenterol. Hepatol. 17: S85-S104.

Ganapathy, B. and N. Suryadevara. Peptic ulcer disease a major concern from Helicobacter pylori's view. Int. J. Adv. Interdiscip. Res. 3(8): 1-9. 
Garg, B., V. Sandhu, N. Sood, A. Sood and V. Malhotra. 2012. Histopathological analysis of chronic gastritis and correlation of pathological features with each other and with endoscopic findings. Pol. J. Pathol. 63(3): 172-178.

Hassan, T. M., S. I. Al-Najjar, I. H. Al-Zahrani, F. I. Alanazi and M. G. Alotibi. 2016. Helicobacter pylori chronic gastritis updated Sydney grading in relation to endoscopic findings and Helicobacter pylori IgG antibody: Diagnostic methods. J. Microsc. Ultrastruct. 4(4): 167-174.

Ibis, M., M. Arhan and B. Odemis. 2009. The relation between endoscopically diagnosed gastritis and its histologic findings. Turk. J. Acad. Gastroenterol. 8: 12-17.

Jeshtadi, A., A. M. Mohammad, M. R. Kadaru, E. A. Nagamuthu, H. Kalangi, A. Boddu, S. K. Lakkarasu and A. Boila. 2016. study of gastric biopsies with clinicopathological correlation a tertiary care centre experience. J. Evid. Based Med. Healthc. 3: 2937-2940.

Kasap, E., G. Güngör, E. Aygör, O. S. Badak, S. Ayhan and H. Yüceyar. 2012. What is the consistency between the diagnoses of endoscopists and pathologists concerning gastroduodenal mucosa. Endoscopy. 20: 13-6.

Kaur, G. and S. M. Raj. 2002. A study of the concordance between endoscopic gastritis and histological gastritis in an area with a low background prevalence of Helicobacter pylori infection. Singapore Med. J. 43(2): 90-92.

Nessa, J., H. Chart, R. J. Owen and B. Drasar. 2001. Human serum antibody response to Helicobacter pylori whole cell antigen in an institutionalized Bangladeshi population. J. Appl. Microbiol. 90(1): 68-72.

Pailoor, K., M. K. Sarpangala and R. C. N. Naik. 2013. Histopathological diagnosis of gastric biopsies in correlation with endoscopy a study in a tertiary care center. Adv. Lab. Med. Int. 3(2): 21-31.

Poudel, A., S. Regmi, S. Poudel and P. Joshi. 2013. Correlation between endoscopic and histopathological findings in gastric lesions. J. Univ. Coll. Med. Sci. 1(3): 37-41.

Ramakrishnan, K. and R. C. Salinas. 2007. Peptic ulcer disease. 76(7): 1005-1012.

Sharma, S., R. Makaju, R. Dhakal, B. Purbey, R. B. Gurung and R. Shrestha. 2015. Correlation between endoscopic and histopathological findings in gastric lesions. Kathmandu Univ. Med. J. 13(3): 216-219.

Sultana, A., S. M. Badruddoza and F. Rahman. 2011. Correlation between endoscopic and histological findings in different gastroduodenal lesion and its association with Helicobacter pylori. Anwer Khan Mod. Med. Coll. J. 2(2): 6-10.

U.S. Department of Health and Human Services. 2010. NSAID's and Peptic Ulcers, National Digestive Diseases Information Clearing House, NIH Publication Ltd., London. p4644.

Versalovic, J. 2003. Helicobacter pylori: Pathology and diagnostic strategies. Am. J. Clin. Pathol. 119(3): 403-412.

Watari, J., N. Chen, P. S. Amenta, H. Fukui, T. Oshima, T. Tomita, H. Miwa, K. J. Lim and K. M. Das. 2014. Helicobacter pylori associated chronic gastritis, clinical syndromes, precancerous lesions, and pathogenesis of gastric cancer development. World J. Gastroenterol. 20(18): 5461.

Yakoob, M. Y. and A. S. Hussainy. 2010. Chronic gastritis and Helicobacter pylori: A histopathological study of gastric mucosal biopsies. J. Coll. Phys. Surg. Pak. 20(11): 773.

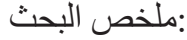

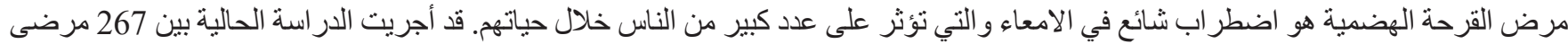

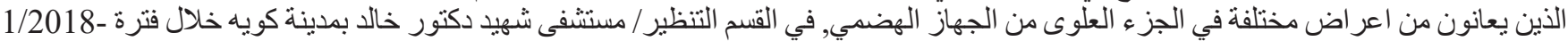

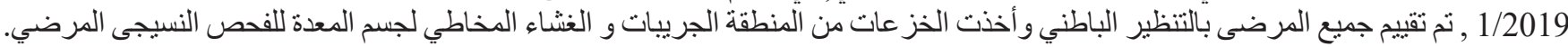
كان الهدف من هذه الار اسة هو تحديد مدى الخزعات النسيجية للمعدة مع توزيع خزعة القرحة الهضمية وفقا للعمر و الجنس

أظهرت الدر اسة, حالة طبيعية للغشاء المخاطي للمعدة في 22 (8.24\%) من الحالات و 245 (8\% (91.76\%) حالة غير طبيعية لغشاء المخاطي في المعدة,

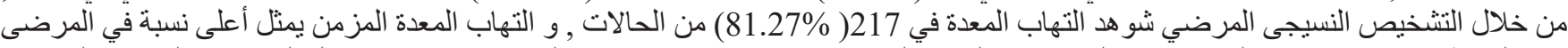

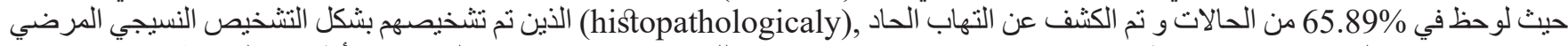

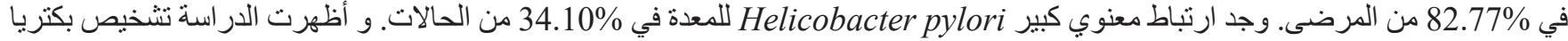
Helicobacter pylori.

يوخته

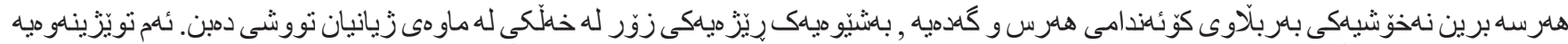

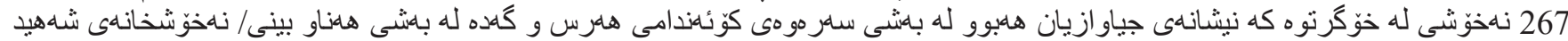

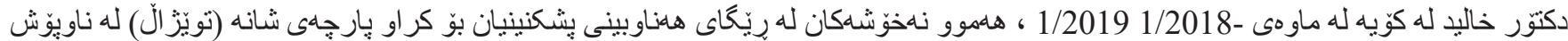

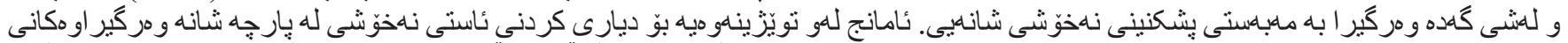

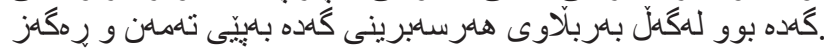

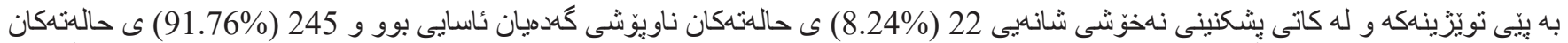

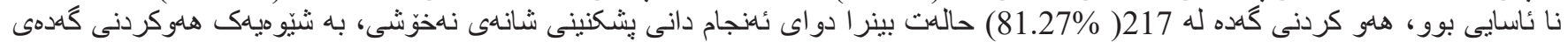

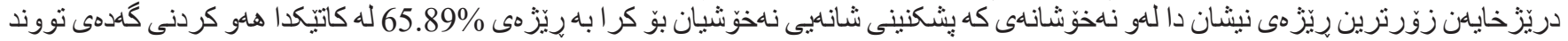

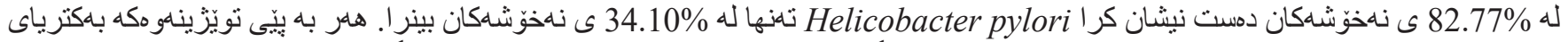

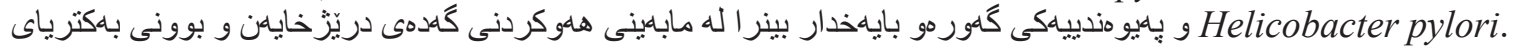

